\title{
Where ergonomics meets geriatrics: the connection between comprehensive geriatric assessment and design for ageing
}

\author{
Tischa J. M. van der Cammen ${ }^{1,2}$ (1) $\cdot$ Gubing Wang $^{1} \cdot$ Armagan Albayrak $^{1}$
}

Received: 3 January 2019 / Accepted: 27 January 2019 / Published online: 8 February 2019

(c) European Geriatric Medicine Society 2019

Keywords Ageing $\cdot$ Ergonomics $\cdot$ Human factors $\cdot$ Comprehensive geriatric assessment $\cdot$ Capability consideration · Technology

Ageing is a multidimensional process of change in the physical, mental, and social domains, leading to functional decline.

Comprehensive geriatric assessment (CGA) is the core technology for assessing older complex patients, and is defined as a multidimensional, multidisciplinary process which identifies medical, social and functional needs, and the development of an integrated care plan to meet those needs $[1,2]$. The purpose of CGA is to identify treatable diseases, improve diagnostic accuracy, optimize medical treatment, improve medical outcomes, optimize living location, minimize unnecessary service use, and arrange long-term case management.

Ageing ergonomics is design driven and studies the agerelated changes in physical, cognitive and organizational capabilities, with a focus on studying and reinforcing the remaining capabilities of older persons.

There are many similarities between the principles of geriatric medicine and ergonomics (see Table 1). Ergonomics studies "the interactions between humans and other elements of a system, and applies theories, principles, data, and methods to design for optimizing human well-being and system performance" [3]. The domain of ergonomics in ageing has investigated the age-related capability changes in the aspects of sensory, cognition and movement capability [4]. The age-related capability changes explored in the sensory

Tischa J. M. van der Cammen

t.j.m.vandercammen@tudelft.nl

1 Faculty of Industrial Design Engineering, Delft University of Technology, Building: 32, Room C-3-180, Landbergstraat 15, 2628 CE Delft, The Netherlands

2 Section of Geriatric Medicine, Department of Internal Medicine, Erasmus University Medical Center, Rotterdam, The Netherlands aspect are visual, auditory, olfactory, and somatosensory capabilities. The capability changes studied in the cognition aspect are memory, attention, and executive control. The capability changes investigated in the movement aspect are muscular strength, movement speed, balance and locomotion [4]. Some capabilities (e.g., vision, working memory) have been found to decrease with age $[5,6]$, while some have been reported to remain relatively stable (e.g., semantic memory) [7]. These discoveries have been transformed into design principles and applied into the adaptation of working place, products and services for older adults, with reported enhancement in both their performance and well-being [8]. Recently, the application of these discoveries has expanded into the medical field, specifically, for developing and evaluating non-pharmacological interventions and their clinical trials for behavioural and psychological symptoms of dementia [9]. In the Agile Co-Creation for Robots and Aging (ACCRA) Project 'New technological solutions for older people', the development of advanced ICT robotics-based solutions for extending active and healthy ageing in daily life is explored by defining, developing and demonstrating an agile co-creation development process [10].

Design for Ageing is closely related to ageing ergonomics and applies a user-centred approach. It aims to support the older adults in their remaining capabilities and compensate for the limitations which they experience in daily life by means of products and services. To develop useful products and services for older adults, their needs, preferences and desires for technology in their lives should be identified and they should be involved in the design process [11]. The focus areas of Design for Ageing should be the so-called geriatric giants, the traditional challenges of ageing such as design for falls prevention, design for dementia care, design for integrated as opposed to fragmented care [12]. The shifting healthcare delivery from the hospital to 
Table 1 Hallmarks of and similarities between CGA and ergonomics in design

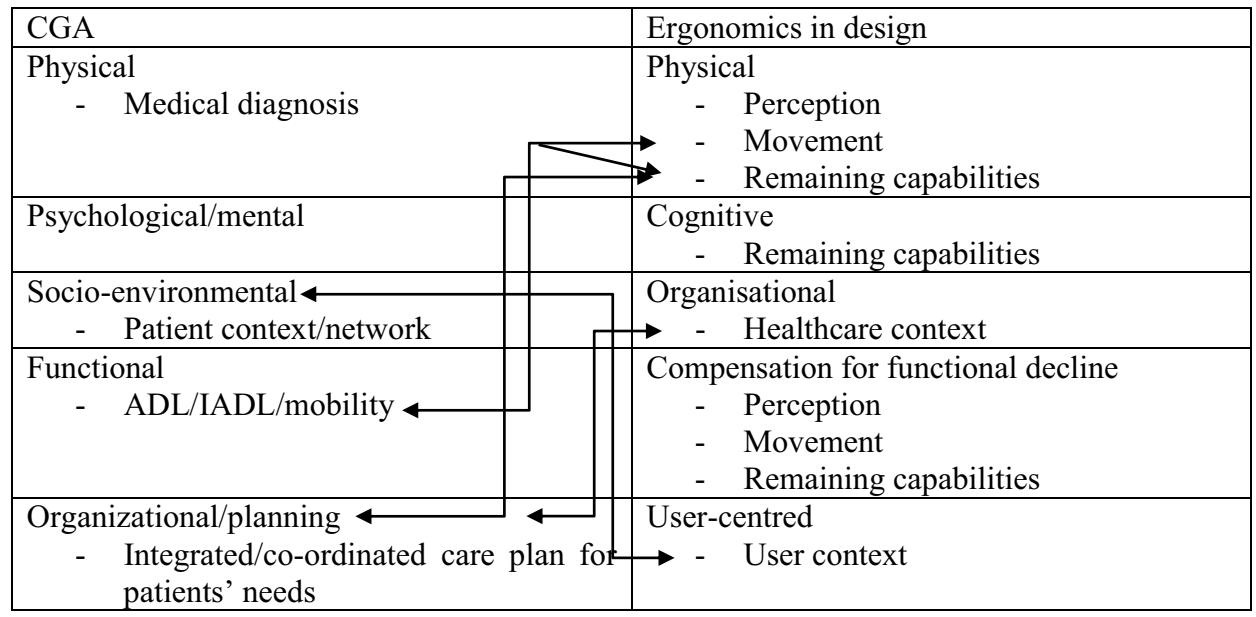

home has the potential to deliver more personalised care to older adults which makes a user-centred design approach even more important. Tackling these challenges in a 'homebased healthcare setting', where the quality of professional care is integrated with the social care will be one of the main topics of the near future.

Considering the principles of geriatric medicine and ageing ergonomics (HF), remarkable similarities can be found between the two disciplines. The fact that both disciplines apply the same multidisciplinary approach to ageing and ageing individuals opens a broad perspective for successful interventions. These interventions can only be successful by following a user-centred design approach as a bridge between the two disciplines. In the White Paper Human Factors for Health and Social Care, the authors describe how human factors and ergonomics can bring depth and clarity of understanding to health and social care issues [13]. In this regard, ergonomics (HF) has a critical and fundamental part to play in patient safety by providing methods and approaches which address known issues of integration, impact and sustainability of change [13].

The European Institute of Innovation \& Technology (EIT) Health has recently published their 2020 Business Plan Calls and one of the focus areas is 'Bringing Care Home' [14]. The aim is to deliver optimal home-based healthcare to older citizens, and consequent financial benefits to society, by designing and demonstrating innovation in home care services and systems. These kind of challenges can only be addressed by integrating geriatric medicine and ageing ergonomics (HF) by following a human-centred design approach.

\section{Compliance with ethical standards}

Conflict of interest The authors declare that they have no conflict of interest.
Ethical approval This article does not contain any studies with human participants or animals performed by any of the authors.

Informed consent For this type of study, formal consent is not required.

\section{References}

1. Ellis G, Whitehead MA, O'Neill D, Langhorne P, Robinson D (2011) Comprehensive geriatric assessment for older adults admitted to hospital. Cochrane Database Syst Rev. https://doi. org/10.1002/14651858.CD006211.pub2

2. Parker SG, McLeod A, McCue P, Phelps K, Bardsley M, Roberts $\mathrm{HC}$ et al (2017) New horizons in comprehensive geriatric assessment. Age Ageing 46(5):713-721

3. Karwowski W (2012) The discipline of human factors and ergonomics. In: Salvendy G (ed) Handbook of human factors and ergonomics. Wiley, Hoboken, pp 1-37

4. Boot WR, Nichols TA, Rogers WA, Fisk AD (2012) Design for aging. In: Salvendy G (ed) Handbook of human factors and ergonomics. Wiley, Hoboken, pp 1442-1471

5. Jackson GR, Owsley C, McGwin G (1999) Aging and dark adaptation. Vis Res 39:3975-3982

6. Voelcker-Rehage C, Stronge A, Alberts J (2006) Age-related differences in working memory and force control under dualtask conditions. Aging Neuropsychol Cognit 13:366-384

7. Zacks RT, Hasher L, Li KZH (2000) Human memory. In: Salthouse TA, Craik FIM (eds) Handbook of aging and cognition. Lawrence Erlbaum, Mahwah, pp 293-357

8. Farage MA, Miller KW, Ajayi F, Hutchins D (2012) Design principles to accommodate older adults. Glob J Health Sci $4: 2-25$

9. Wang G, Albayrak A, van der Cammen T (2018) A systematic review of non-pharmacological interventions for BPSD in nursing home residents with dementia: from a perspective of ergonomics. Int Psychogeriatr. https://doi.org/10.1017/S1041610218001679

10. D'Onofrio G, Fiorini L, de Mul M et al (2018) Agile co-creation for robots and aging (ACCRA) project: new technological solutions for older people. Eur Geriatr Med 9(6):795-800

11. Rogers WA, Fisk AD (2010) Toward a psychological science of advanced technology design for older adults. J Gerontol: Psychol Sci 65B(6):645-653 
12. Van der Cammen TJ, Albayrak A, Voûte E, Molenbroek JF (2017) New horizons in design for autonomous ageing. Age Ageing 46(1):11-17

13. Chartered Institute of Ergonomics and Human Factors, Hignett $\mathrm{S}$ and Lang A. Human factors for health and social care (white paper); 2018; Birmingham: CIEHF. https://dspace.lboro.ac.uk/ dspace-jspui/handle/2134/35447/. Accessed 19 Dec 2018
14. https://www.eithealth.eu/-/sparking-ideas-for-healthcare-solut ions-in-areas-of-bringing-care-home-and-real-world-data-/. Accessed 19 Dec 2018

Publisher's Note Springer Nature remains neutral with regard to jurisdictional claims in published maps and institutional affiliations. 